\title{
LEVANTAMENTO FITOSSOCIOLÓGICO DE PLANTAS DANINHAS NA CULTURA DO FEIJÃO-CAUPI
}

Arlete da Silva Bandeira ${ }^{1}$, Raelly da Silva Lima ${ }^{1}$, Ednilson Carvalho Teixeira ${ }^{2}$, Renan Thiago Carneiro Nunes ${ }^{1}$, Victor Rosário de Novais ${ }^{3}$, Ubiratan Oliveira Souza ${ }^{4}$, Everardes Públio Júnior ${ }^{5}$

${ }^{1}$ Doutorando(a), Agronomia, Universidade Estadual do Sudoeste da Bahia (UESB), Vitória da Conquista BA.

*E-mail: arletebandeira@yahoo.com.br

${ }^{2}$ Mestrando, Agronomia, Universidade Estadual do Sudoeste da Bahia (UESB), Vitória da Conquista - BA.

${ }^{3}$ Graduando, Agronomia, Universidade Estadual do Sudoeste da Bahia (UESB), Vitória da Conquista - BA.

${ }^{4}$ Professor do Instituto Federal de Educação, Ciência e Tecnologia Baiano/Campus de Bom Jesus da Lapa BA.

${ }^{5}$ Professor do Instituto Federal de Educação, Ciência e Tecnologia Baiano/Campus Paulo Afonso - BA.

RESUMO: A presença das plantas daninhas nas áreas agrícolas contribui para o aumento dos custos de produção, além de interferir na produtividade e na qualidade do produto final da cultura de interesse. Diante do exposto, o objetivo deste trabalho foi verificar a composição de plantas daninhas presentes na área de cultivo do feijão-caupi em Vitória da Conquista, BA. As avaliações foram realizadas mediante ao lançamento aleatório de um quadrado vazado de $0,25 \mathrm{~m}^{2}$, lançado, aleatoriamente, aos $7,14,21,28,35,42,49,56$ e 63 dias após a emergência (DAE) do feijão-caupi. As plantas abrangidas pelo quadrado de amostragem foram recolhidas, contadas e identificadas. Foram identificadas 43 espécies de plantas daninhas distribuídas em 36 gêneros e 17 famílias botânicas. As principais famílias encontradas foram Poaceae (nove espécies), Asteraceae (seis espécies) e Malvaceae (seis espécies) e, dentre as classes botânicas, destacou-se as eudicotiledôneas (77 \%). As espécies que apresentaram maiores valores para frequência relativa, densidade relativa, abundância relativa e índice de valor de importância (IVI) foram Portulaca mucronata, Digitaria horizontalis e Panicum maximum. As espécies $D$. horizontalis e $P$. maximum aparesentaram maiores IVI aos 7 e 21 dias após a emergência da cultura, respectivamente.

Palavras-chave: Competição. Composição florística. Leguminosa. Vigna unguiculata (L.)

\section{PHYTOSOCIOLOGICAL ANALYSIS OF WEED COMMUNITY IN A COWPEA CROP}

\begin{abstract}
The presence of weeds in the agricultural areas contributes to the increase of the production costs, besides interfering in the productivity and quality of the final product of the crop of interest. In view of the above, the objective of this work was to verify the composition of weeds present in the area of cowpea in Vitória da Conquista, BA. The evaluations were performed by randomly casting a $0.25 \mathrm{~m} 2$ cast square, randomly, at 7,14 , 21, 28, 35, 42, 49, 56 and 63 days after emergence (DAE) cowpea. The plants covered by
\end{abstract}


the sampling square were collected, counted and identified. A total of 43 weed species distributed in 36 genera and 17 botanical families were identified. The main families were Poaceae (nine species), Asteraceae (six species) and Malvaceae (six species), and among the botanical classes, eudicotyledonous $(77 \%)$ were highlighted. The species that presented the highest values for relative frequency, relative density, relative abundance and import value index (IVI) were Portulaca mucronata, Digitaria horizontalis and Panicum maximum. The species $D$. horizontalis and $P$. maximum showed higher IVI at 7 and 21 days after emergence of the culture, respectively.

Key words: Vigna unguiculata (L.). Legume. Competition. Flower composition.

\section{INTRODUÇÃO}

O feijão-caupi, feijão-de-corda ou feijão-fradinho (Vigna unguiculata) (L.) Walp.) é uma leguminosa de grande importância para as regiões Norte e Nordeste por constituir a base alimentar para as populações, principalmente as mais carentes. Possui um alto valor nutricional sendo, portanto, um dos principais componentes da dieta alimentar, além de garantir a geração de emprego e renda, tanto na zona rural, quanto na zona urbana (FREIRE FILHO et al., 2011).

Nos últimos anos, a cultura vem despertando o interesse dos produtores que praticam a agricultura empresarial, em razão do desenvolvimento de cultivares com características que favorecem o cultivo mecanizado. Entretanto, como qualquer outra espécie agrícola, essa também é afetada por fatores ecológicos que podem prejudicar o seu rendimento de forma direta ou indireta (MARQUES et al., 2010).

A convivência com plantas daninhas é considerada um dos principais fatores que interferem na produtividade do feijão-caupi, pois a cultura é altamente suscetível à competição, cujas perdas no rendimento de grãos pode chegar em até $90 \%$ durante todo o ciclo (FREITAS et al., 2009). De acordo com os autores, além de refletir na redução quantitativa e qualitativa da produção, as plantas daninhas constituem um dos fatores que mais influenciam o crescimento, o desenvolvimento e a produtividade da cultura, por competir por água, luz e nutrientes.

Para o controle adequado das plantas daninhas presentes na área torna necessário a identificação das espécies, assim como o conhecimento daquelas de maior importância (OLIVEIRA e FREITAS, 2008). Tais informações podem ser obtidas a partir do levantamento fitossociológico de uma determinada lavoura.

Os estudos fitossociológicos permitem a realização de repetições programadas dos estudos florísticos, podendo indicar tendências de variação da importância de uma ou mais populações (OLIVEIRA e FREITAS, 2008). E a partir da caracterização da comunidade infestante, torna-se possível obter um embasamento técnico para, posteriormente, contribuir na escolha das estratégias de manejo e de controle a serem empregadas nos sistemas 
agrícolas, reduzindo, com isto, nos custos de produção e impacto ambiental (ISAAC e GUIMARÃES, 2008).

Os aspestos fitossociológicos podem revelar também as inter-relações das espécies no espaço e no tempo, possibilitando a avaliação da composição da vegetação, para a obtenção de dados como: frequência, densidade, abundância e índice de valor de importâcia das espécies (PINOTTI et al., 2010). O índice de valor de importância, informam, numericamente, a importância de uma determinada espécie na comunidade, sendo determinado através da soma de seus valores de frequiência, densidade e abundância, expresso em porcentagem (FREITAS e MAGALHÃES, 2012).

Objetivou-se neste trabalho identificar e quantificar a composição florística das principais espécies de plantas daninhas no cultivo do feijão-caupi, na área experimental da Universidade Estadual do Sudoeste da Bahia, campus de Vitória da Conquista-BA.

\section{MATERIAL E MÉTODOS}

O levantamento fitossociológico foi realizado na área experimental da Universidade Estadual do Sudoeste da Bahia, durante o cultivo de feijão-caupi, no municipio de Vitória da Conquista-BA, durante os meses de dezembro de 2013 a fevereiro de 2014. O município está localizado na microrregião do Planalto de Conquista, Sudoeste da Bahia, numa altitude de 900 metros, com as coordenadas geográficas de $14^{\circ} 53^{\prime}$ de latitude Sul e $40^{\circ} 48^{\prime}$ de longitude Oeste. Conforme a classificação de Köppen, o clima regional é classificado como tropical de altitude (Cwa), com precipitação média anual de 733,9 mm. O solo da área experimental foi classificado como Latossolo Amarelo Distrófico Típico, com textura franco argilo-arenosa.

O preparo periódico do solo foi feito com uma aração e duas gradagens e a cultura utilizada foi o feijão-caupi, cultivar BRS Guariba. A semeadura foi realizada, manualmente, em dezembro de 2013, utilizando-se 8 sementes por metro linear, com espaçamento entre fileiras de $0,50 \mathrm{~m}$.

Tabela 1. Médias mensais de precipitação (Prec.), umidade relativa do ar (UR), temperatura máxima (Tmáx.) e temperatura mínima (Tmín.), no período de dezembro/2013 a fevereiro/2014 (Vitória da Conquista/BA, 2015).

\begin{tabular}{ccccc}
\hline Mês/Ano & Prec. $(\mathrm{mm})$ & UR\% & Tmáx $\left({ }^{\circ} \mathrm{C}\right)$ & Tmín $\left({ }^{\circ} \mathrm{C}\right)$ \\
\hline dez/13 & 232,70 & 77,63 & 27,46 & 16,91 \\
jan/13 & 69,60 & 76,57 & 26,90 & 15,48 \\
fev/13 & 35,80 & 77,25 & 27,36 & 15,04
\end{tabular}

Fonte: Instituto Nacional de Meteorologia Estação Meteorológica - INMET. Vitória da Conquista - BA, 2015.

Os dados climáticos de precipitação pluvial, umidade relativa do ar e temperaturas médias máximas e mínimas, durante o período de realização do experimento (dezembro de 
2013 a fevereiro de 2014), estão apresentados na Tabela 1. Durante o desenvolvimento da cultura e na ausência de chuvas, utilizou-se irrigação suplementar por aspersão convencional, visando atender às demandas hídricas da cultura.

A quantificação e a identificação das espécies de plantas daninhas foram realizadas mediante ao lançamento aleatório de um quadrado vazado de $0,25 \mathrm{~m}^{2}(0,5 \mathrm{x} 0,5 \mathrm{~m})$, lançado, aleatoriamente, aos 7, 14, 21, 28, 35, 42, 49, 56 e 63 dias após a emergência (DAE) do feijão-caupi. A área de cada ponto onde se realizou a amostragem foi de $12,5 \mathrm{~m}^{2}(5 \mathrm{~m}$ de comprimento x 2,5 m de largura), totalizando $1.100 \mathrm{~m}^{2}$. Foram realizadas 44 amostragens em cada período, com um total de 360 amostragens.

As partes aéreas das plantas daninhas situadas nas áreas amostradas foram seccionadas rente ao solo e, em seguida, foram identificadas por família, gênero e espécie (LORENZI, 2008).

Após a identificação e obtenção dos dados das espécies coletadas, realizou-se a análise descritiva por meio de parâmetros fitossociológicos: Frequência relativa (Fr): (frequência da espécie x 100)/frequência total das espécies; Densidade Relativa (Dr): (densidade da espécie x 100)/densidade total de todas as espécies; Abundância relativa (Ar): (abundância da espécie x 100)/abundância total de todas as espécies; Índice de Valor de Importância (IVI): frequência relativa + densidade relativa + abundância relativa (MUELLER-DOMBOIS e ELLENBERG, 1974).

\section{RESULTADOS E DISCUSSÃO}

\section{Identificação e quantificação da comunidade infestante}

Na Tabela 2 pode ser observada a relação de espécies amostradas durante todo o ciclo da cultura do feijão-caupi, suas respectivas famílias, nomes comuns, códigos internacionais da Weed Society (COD) e classificação botânica. Foram identificados trinta e seis gêneros e dezessete famílias, perfazendo um total de quarenta e três espécies. Em relação às classes botânicas, predominou-se $77 \%$ de eudicotiledôneas e $23 \%$ de monocotiledôneas. Freitas et al. (2009) e Corrêa et al. (2015), trabalhando com a interferência de plantas daninhas na cultura do feijão-caupi, observaram que a classe botânica das eudicotiledôneas foi a mais predominante, na ordem de $63 \%$ e $82 \%$, respectivamente, corroborando com os resultados obtidos neste trabalho. De acordo com Marques et al. (2010), a predominância das espécies da classe das eudicotiledôneas pode estar relacionada à própria classe de cultivo do feijãocaupi, ou seja, eudicotiledônea.

As principais famílias encontradas foram Poaceae (nove espécies), Asteraceae (seis espécies) e Malvaceae (seis espécies) (Tabela 2). Esses resultados corroboram com o verificado em levantamentos realizados por Marques et al. (2010) e Batista et al. (2016), na cultura do feijão-caupi e feijão-comum, respectivamente, nas quais relatam que, entre as famílias identificadas, as Poaceae, Malvaceae e Asteraceae foram detentoras de maior 
número de espécies.

Tabela 2. Relação das espécies de plantas daninhas identificadas no levantamento fitossociológico realizado na cultura do feijão-caupi, organizadas por nome científico, família, nome comum, código internacional e classificação botânica (Vitória da ConquistaBA, 2015).

\begin{tabular}{|c|c|c|c|c|}
\hline Nome científico & Família & Nome comum & COD* & Classificação \\
\hline$\overline{\text { Amaranthus viridis }}$ & Amaranthaceae & Caruru-de-mancha & AMAVI & $\overline{\text { Eudicotiledônea }}$ \\
\hline Amaranthus hybridus & Amaranthaceae & Caruru-roxo & $\mathrm{AMACH}$ & Eudicotiledônea \\
\hline Acanthospermum australe & Asteraceae & Carrapicho de carneiro & ACNAU & Eudicotiledônea \\
\hline Bidens pilosa & Asteraceae & Picão preto & BIDPI & Eudicotiledônea \\
\hline Blainvillea rhomboidea & Asteraceae & Picão grande & BLARH & Eudicotiledônea \\
\hline Ageratum conyzoides & Asteraceae & Picão roxo & AGECO & Eudicotiledônea \\
\hline Emilia sonchifolia & Asteraceae & Falsa-serralha & EMISO & Eudicotiledônea \\
\hline Parthenium hysterophorus & Asteraceae & Losna-branca & PTNHY & Eudicotiledônea \\
\hline Pyrostegia venusta & Bignoniaceae & Cipó-de-são-joão & PYRVE & Eudicotiledônea \\
\hline Senna obtusifolia & Caesalpinoideae & Fedegoso & CASOB & Eudicotiledônea \\
\hline Chenopodium carinatum & Chenopodiaceae & Anserina-rendada & CHEPU & Eudicotiledônea \\
\hline Chenopodium album & Chenopodiaceae & Fedegosa & CHEAL & Eudicotiledônea \\
\hline Ipomoea triloba & Convolvulaceae & Corda-de-viola & IPOTR & Eudicotiledônea \\
\hline Dichondra sericea & Convolvulaceae & orelha-de-rato & --- & Eudicotiledônea \\
\hline Croto heliotropiifolius & Euphorbiaceae & Velame & --- & Eudicotiledônea \\
\hline Hyptis suaveolens & Lamiaceae & Cheirosa & HPYSU & Eudicotiledônea \\
\hline Herissantia crispa & Malvaceae & Mela-bode & ABUCR & Eudicotiledônea \\
\hline $\begin{array}{l}\text { Malvastrum } \\
\text { coromandelianum }\end{array}$ & Malvaceae & Falsa-guanxuma & MAVCO & Eudicotiledônea \\
\hline Pavonia cancellata & Malvaceae & Malva-rasteira & PVACD & Eudicotiledônea \\
\hline Pavonia sidifolia & Malvaceae & Vassoura & PVAST & Eudicotiledônea \\
\hline Sida cordifolia & Malvaceae & Guanxuma & SIDCO & Eudicotiledônea \\
\hline Sida rhombifolia & Malvaceae & Guanxuma & SIDRH & Eudicotiledônea \\
\hline Mollugo verticillata & Molluginaceae & Capim tapete & MOLVE & Eudicotiledônea \\
\hline Crotalaria indica & Papilionoideae & Chocalho-de-cascavel & CVTIN & Eudicotiledônea \\
\hline Desmodium adscendentes & Papilionoideae & Amorico & DEDAD & Eudicotiledônea \\
\hline Portulaca oleracea & Portulacaceae & Beldroega & POROL & Eudicotiledônea \\
\hline Portulaca mucronata & Portulacaceae & Onze horas & --- & Eudicotiledônea \\
\hline Richardia scabra & Rubiaceae & Mata-pasto & RCHSC & Eudicotiledônea \\
\hline Diodia teres & Rubiaceae & Engana-bobo & DIQTE & Eudicotiledônea \\
\hline Solanum americanum & Solanaceae & Maria-pretinha & SOLAM & Eudicotiledônea \\
\hline Solanum paniculatum & Solanaceae & Jurubeba & SOLPA & Eudicotiledônea \\
\hline Solanum mauritianum & Solanaceae & Fumo-bravo & --- & Eudicotiledônea \\
\hline Waltheria indica & Sterculiaceae & Malva-branca & WALAM & Eudicotiledônea \\
\hline Aeschynomene denticulata & Poaceae & Angiquinho & AESDE & Monocotiledônea \\
\hline Brachiaria plantaginea & Poaceae & Capim marmelada & BRAPL & Monocotiledônea \\
\hline Cenchrus echinatus & Poaceae & Capim carrapicho & CCHEC & Monocotiledônea \\
\hline Cynodon dactylon & Poaceae & Capim seda & CYNDA & Monocotiledônea \\
\hline
\end{tabular}

Cultura Agronômica, Ilha Solteira, v.27, n.2, p.327-340, 2018 
Tabela 2. Continuação...

\begin{tabular}{lcccc}
\hline \multicolumn{1}{c}{ Nome científico } & Família & Nome comum & COD* & Classificação \\
\hline \multirow{2}{*}{$\begin{array}{l}\text { Digitaria horizantalis } \\
\text { Eleusine indica }\end{array}$} & Poaceae & Capim colchão & DIGHO & Monocotiledônea \\
Panicum maximum & Poaceae & Capim-pé-de-galinha & ELEIN & Monocotiledônea \\
Setaria geniculata & Poaceae & Capim colonião & PANMA Monocotiledônea \\
Rhynchelytrum repens & Poaceae & Capim-rabo-de-raposa & SETGE & Monocotiledônea \\
Commelina benghalensis & Poaceae & Capim favorito & RHYRE & Monocotiledônea \\
\hline
\end{tabular}

*Códigos internacionais das Weed Society.

Oliveira et al. (2017), ao avaliar a variabilidade fitossociológica das plantas daninhas na cultura do feijão-caupi no agreste Alagoano, observaram que as famílias Poaceae e Asteraceae foram as que mais ocorreram na área. De acordo com Oliveira e Freitas (2008), as altas densidades da família Poaceae e Asteraceae em determinado local ou região, são justificadas pelo fato de que ambas são consideradas as principais famílias de plantas daninhas predominantes no Brasil. Além disso, estes resultados mostram a grande importância dessas famílias nos diferentes sistemas de cultivos, em diferentes culturas e regiões, especialmente devido ao potencial agressivo das plantas daninhas pertencentes a essas famílias (SANTI et al., 2014).

\section{Parâmetros fitossociológicos da comunidade infestante}

Em todos os períodos de avaliação as espécies Digitaria horizontalis, Panicum maximume Portulaca mucronata apresentaram maiores valores para frequência relativa (FR), densidade relativa (DR), abundância relativa (AR) e índice de valor de importância (IVI) (Tabelas 3, 4 e 5).

O índice de valor de importância, representado pelo somatório da frequência relativa, da densidade relativa e da abundância relativa mostra qual espécie tem maior influência dentro de uma comunidade (FREITAS e MAGALHÃES, 2012). Neste trabalho, os maiores índices de valor de importância foram observados para $D$. horizontalis $(118,57)$ no período de 7 dias após a emergência (DAE) da cultura e $P$. maximum $(54,22)$ no período de 21 DAE (Tabela 3). Os elevados valores de índice de valor de importância para a espécie $D$. horizontalis foi resultado da alta densidade relativa. Para essa espécie observou-se uma distribuição uniforme na área, durante o ciclo inicial da cultura, provavelmente, devido ao banco de sementes no solo formado no período que a área estava em pousio, possibilitando sua retomada de crescimento em poucos dias. Corroborando com esses resultados, Silva et al. (2018), ao estudarem a caracterização de plantas daninhas em área rotacionada de milho e feijão-caupi em plantio direto, verificaram que $D$. horizontalis apresentou maior IVI $(44,66 \%)$. De acordo com os autores, isso se deve ao fato de que a espécie D. horizontalis possui menor sensibilidade a luz durante a germinação de seus propágulos e a utilização de cobertura morta, em rotações anteriores ao feijão-caupi, promoveu a seleção da espécie.

Cultura Agronômica, Ilha Solteira, v.27, n.2, p.327-340, 2018 
Tabela 3. Parâmetros fitossociológicos das espécies de plantas daninhas, em ordem decrescente de número de presença em quadrados (NQ), número de indivíduos (NI), frequência relativa (FR), densidade relativa (DR), abundância relativa (AR) e índice de valor de importância (IVI) coletadas aos 7, 14 e 21 dias após a emergência do feijão-caupi (Vitória da Conquista-BA, 2015).

\begin{tabular}{|c|c|c|c|c|c|c|c|c|c|c|c|c|c|c|c|c|c|c|}
\hline \multirow{3}{*}{ Espécies } & \multicolumn{6}{|c|}{$7 \mathrm{DAE}$} & \multicolumn{6}{|c|}{$14 \mathrm{DAE}$} & \multicolumn{6}{|c|}{$21 \mathrm{DAE}$} \\
\hline & NQ & NI & FR & DR & AR & IVI & NQ & $\mathrm{NI}$ & FR & DR & AR & IVI & NQ & NI & FR & DR & AR & IVI \\
\hline & \multicolumn{6}{|c|}{---------\%"-------- } & \multicolumn{8}{|c|}{---------\%"-------- } & \multicolumn{4}{|c|}{--------\%-------- } \\
\hline Digitaria horizontalis & 31 & 181 & 36,05 & 67,04 & 15,49 & 118,57 & 29 & 103 & 30,85 & 51,24 & 11,98 & 94,08 & 15 & 49 & 13,39 & 23,56 & 9,90 & 46,85 \\
\hline Portulaca oleracea & 13 & 22 & 15,12 & 8,15 & 4,49 & 27,75 & 3 & 8 & 3,19 & 3,98 & 9,00 & 16,17 & 5 & 6 & 4,46 & 2,88 & 3,64 & 10,98 \\
\hline Brachiaria plantaginea & 6 & 8 & 6,98 & 2,96 & 3,54 & 13,48 & 11 & 15 & 11,70 & 7,46 & 4,60 & 23,77 & 3 & 3 & 2,68 & 1,44 & 3,03 & 7,15 \\
\hline Senna obtusifolia & 5 & 9 & 5,81 & 3,33 & 4,77 & 13,92 & 3 & 3 & 3,19 & 1,49 & 3,37 & 8,06 & 2 & 2 & 1,79 & 0,96 & 3,03 & 5,78 \\
\hline Herissantia crispa & 5 & 6 & 5,81 & 2,22 & 3,18 & 11,22 & 9 & 16 & 9,57 & 7,96 & 6,00 & 23,53 & 5 & 6 & 4,46 & 2,88 & 3,64 & 10,98 \\
\hline Malvastrum coromandelianum & 4 & 5 & 4,65 & 1,85 & 3,32 & 9,82 & 6 & 6 & 6,38 & 2,99 & 3,37 & 12,74 & 3 & 6 & 2,68 & 2,88 & 6,06 & 11,62 \\
\hline Blainvillea biaristata & 4 & 5 & 4,65 & 1,85 & 3,32 & 9,82 & 9 & 10 & 9,57 & 4,98 & 3,75 & 18,30 & 9 & 10 & 8,04 & 4,81 & 3,37 & 16,21 \\
\hline Chenopodium album & 3 & 4 & 3,49 & 1,48 & 3,54 & 8,51 & - & - & - & - & - & - & - & - & - & - & - & - \\
\hline Commelina benghalensis & 2 & 2 & 2,33 & 0,74 & 2,65 & 5,72 & - & - & - & - & - & - & - & - & - & - & - & - \\
\hline Panicum maximum & 2 & 9 & 2,33 & 3,33 & 11,94 & 17,60 & 1 & 1 & 1,06 & 0,50 & 3,37 & 4,94 & 23 & 55 & 20,54 & 26,44 & 7,24 & 54,22 \\
\hline Ipomoea triloba & 2 & 3 & 2,33 & 1,11 & 3,98 & 7,42 & - & - & - & - & - & - & - & - & - & - & - & - \\
\hline Crotalaria indica & 2 & 2 & 2,33 & 0,74 & 2,65 & 5,72 & - & - & - & - & - & - & - & - & - & - & - & - \\
\hline Chenopodium carinatum & 1 & 7 & 1,16 & 2,59 & 18,57 & 22,32 & 1 & 1 & 1,06 & 0,50 & 3,37 & 4,94 & - & - & - & - & - & - \\
\hline Pavonia cancellata & 1 & 1 & 1,16 & 0,37 & 2,65 & 4,19 & - & - & - & - & - & - & - & - & - & - & - & - \\
\hline Bidens pilosa & 1 & 1 & 1,16 & 0,37 & 2,65 & 4,19 & - & - & - & - & - & - & - & - & - & - & - & - \\
\hline Sida rhombifolia & 1 & 2 & 1,16 & 0,74 & 5,31 & 7,21 & 1 & 2 & 1,06 & 1,00 & 6,75 & 8,81 & 2 & 2 & 1,79 & 0,96 & 3,03 & 5,78 \\
\hline Cynodon dactylon & 1 & 1 & 1,16 & 0,37 & 2,65 & 4,19 & 1 & 1 & 1,06 & 0,50 & 3,37 & 4,94 & 1 & 1 & 0,89 & 0,48 & 3,03 & 4,40 \\
\hline Amaranthus hybridus & 1 & 1 & 1,16 & 0,37 & 2,65 & 4,19 & 1 & 1 & 1,06 & 0,50 & 3,37 & 4,94 & 4 & 9 & 3,57 & 4,33 & 6,82 & 14,71 \\
\hline Emilia sonchifolia & 1 & 1 & 1,16 & 0,37 & 2,65 & 4,19 & 3 & 3 & 3,19 & 1,49 & 3,37 & 8,06 & 4 & 4 & 3,57 & 1,92 & 3,03 & 8,52 \\
\hline Solanum americanum & - & - & - & - & - & - & - & - & - & - & - & - & 9 & 13 & 8,04 & 6,25 & 4,38 & 18,66 \\
\hline Portulaca mucronata & - & - & - & - & - & - & 9 & 15 & 9,57 & 7,46 & 5,62 & 22,66 & 17 & 28 & 15,18 & 13,46 & 4,99 & 33,63 \\
\hline Pavonia cancellata & - & - & - & - & - & - & - & - & - & - & - & - & 2 & 3 & 1,79 & 1,44 & 4,54 & 7,77 \\
\hline Solanum paniculatum & - & - & - & - & - & - & 2 & 4 & 2,13 & 1,99 & 6,75 & 10,87 & 1 & 1 & 0,89 & 0,48 & 3,03 & 4,40 \\
\hline Ageratum conyzoides & - & - & - & - & - & - & 2 & 9 & 2,13 & 4,48 & 15,18 & 21,79 & 1 & 1 & 0,89 & 0,48 & 3,03 & 4,40 \\
\hline Diodia teres & - & - & - & - & - & - & 2 & 2 & 2,13 & 1,00 & 3,37 & 6,50 & 1 & 4 & 0,89 & 1,92 & 12,12 & 14,93 \\
\hline Chamecrista rotundifolia & - & - & - & - & - & - & - & - & - & - & - & - & 2 & 2 & 1,79 & 0,96 & 3,03 & 5,78 \\
\hline Sida cordifolia & - & - & - & - & - & - & - & - & - & - & - & - & 1 & 1 & 0,89 & 0,48 & 3,03 & 4,40 \\
\hline Cenchrus echinatus & - & - & - & - & - & - & 1 & 1 & 1,06 & 0,50 & 3,37 & 4,94 & - & - & - & - & - & - \\
\hline Setaria geniculata & - & - & - & - & - & - & - & - & - & - & - & - & 1 & 1 & 0,89 & 0,48 & 3,03 & 4,40 \\
\hline$\underline{\text { Sida spinosa }}$ & - & - & - & - & - & - & - & - & - & - & - & - & 1 & 1 & 0,89 & 0,48 & 3,03 & 4,40 \\
\hline Total & 86 & 270 & 100 & 100 & 100 & 300 & 94 & 201 & 100 & 100 & 100 & 300 & 112 & 208 & 100 & 100 & 100 & 300 \\
\hline
\end{tabular}

Cultura Agronômica, Ilha Solteira, v.27, n.2, p.327-340, 2018 
Tabela 4. Parâmetros fitossociológicos das espécies de plantas daninhas, em ordem decrescente de número de presença em quadrados (NQ), número de indivíduos (NI), frequência relativa (FR), densidade relativa (DR), abundância relativa (AR) e índice de valor de importância (IVI) coletadas aos 28, 35 e 42 dias após a emergência do feijão-caupi (Vitória da Conquista-BA, 2015).

\begin{tabular}{|c|c|c|c|c|c|c|c|c|c|c|c|c|c|c|c|c|c|c|}
\hline \multirow[b]{2}{*}{ Espécies } & \multirow[b]{2}{*}{ NQ } & \multirow[b]{2}{*}{ NI } & \multicolumn{4}{|c|}{$28 \mathrm{DAE}$} & \multicolumn{6}{|c|}{$35 \mathrm{DAE}$} & \multirow[b]{2}{*}{ NQ } & \multirow[b]{2}{*}{ NI } & \multicolumn{4}{|c|}{$42 \mathrm{DAE}$} \\
\hline & & & FR & DR & AR & IVI & NQ & NI & FR & $\begin{array}{c}\text { DR } \\
-\%\end{array}$ & AR & IVI & & & FR & $\begin{array}{l}\text { DR } \\
-\%\end{array}$ & AR & IVI \\
\hline Portulaca mucronata & 19 & 37 & 15,70 & 16,37 & 5,29 & 37,36 & 17 & 21 & 14,53 & 13,29 & 3,89 & 31,71 & 10 & 16 & 7,94 & 5,82 & 3,59 & 17,35 \\
\hline Panicum maximum & 18 & 35 & 14,88 & 15,49 & 5,28 & 35,64 & 13 & 21 & 11,11 & 13,29 & 5,09 & 29,49 & 28 & 86 & 22,22 & 31,27 & 6,90 & 60,39 \\
\hline Digitaria horizontalis & 11 & 39 & 9,09 & 17,26 & 9,63 & 35,97 & 5 & 8 & 4,27 & 5,06 & 5,04 & 14,38 & 4 & 17 & 3,17 & 6,18 & 9,54 & 18,90 \\
\hline Herissantia crispa & 10 & 13 & 8,26 & 5,75 & 3,53 & 17,55 & 10 & 10 & 8,55 & 6,33 & 3,15 & 18,03 & 8 & 10 & 6,35 & 3,64 & 2,81 & 12,79 \\
\hline Solanum americanum & 10 & 11 & 8,26 & 4,87 & 2,99 & 16,12 & 10 & 10 & 8,55 & 6,33 & 3,15 & 18,03 & 11 & 16 & 8,73 & 5,82 & 3,27 & 17,82 \\
\hline Sida cordifolia & 8 & 17 & 6,61 & 7,52 & 5,77 & 19,90 & 6 & 6 & 5,13 & 3,80 & 3,15 & 12,08 & 5 & 17 & 3,97 & 6,18 & 7,64 & 17,79 \\
\hline Blainvillea biaristata & 6 & 7 & 4,96 & 3,10 & 3,17 & 11,22 & 6 & 6 & 5,13 & 3,80 & 3,15 & 12,08 & 6 & 11 & 4,76 & 4,00 & 4,12 & 12,88 \\
\hline Cynodon dactylon & 6 & 17 & 4,96 & 7,52 & 7,69 & 20,17 & 6 & 9 & 5,13 & 5,70 & 4,73 & 15,55 & 4 & 4 & 3,17 & 1,45 & 2,25 & 6,88 \\
\hline Sida rhombifolia & 5 & 6 & 4,13 & 2,65 & 3,26 & 10,05 & 1 & 1 & 0,85 & 0,63 & 3,15 & 4,64 & 4 & 5 & 3,17 & 1,82 & 2,81 & 7,80 \\
\hline Portulaca oleracea & 4 & 14 & 3,31 & 6,19 & 9,50 & 19,00 & - & - & - & - & - & - & 2 & 4 & 1,59 & 1,45 & 4,49 & 7,53 \\
\hline Setaria geniculata & 4 & 4 & 3,31 & 1,77 & 2,72 & 7,79 & 7 & 14 & 5,98 & 8,86 & 6,30 & 21,15 & 4 & 11 & 3,17 & 4,00 & 6,18 & 13,35 \\
\hline Brachiaria plantaginea & 3 & 1 & 2,48 & 0,44 & 0,91 & 3,83 & 4 & 12 & 3,42 & 7,59 & 9,45 & 20,47 & 8 & 26 & 6,35 & 9,45 & 7,30 & 23,10 \\
\hline Solanum paniculatum & 3 & 7 & 2,48 & 3,10 & 6,34 & 11,91 & 1 & 1 & 0,85 & 0,63 & 3,15 & 4,64 & 4 & 12 & 3,17 & 4,36 & 6,74 & 14,28 \\
\hline Senna obtusifolia & 2 & 3 & 1,65 & 1,33 & 4,07 & 7,05 & 1 & 1 & 0,85 & 0,63 & 3,15 & 4,64 & 1 & 1 & 0,79 & 0,36 & 2,25 & 3,40 \\
\hline Pavonia cancellata & 2 & 4 & 1,65 & 1,77 & 5,43 & 8,85 & 1 & 1 & 0,85 & 0,63 & 3,15 & 4,64 & 2 & 2 & 1,59 & 0,73 & 2,25 & 4,56 \\
\hline Commelina benghalensis & 2 & 2 & 1,65 & 0,88 & 2,72 & 5,25 & - & - & - & - & - & - & 4 & 11 & 3,17 & 4,00 & 6,18 & 13,35 \\
\hline Richardia scabra & 2 & 2 & 1,65 & 0,88 & 2,72 & 5,25 & 1 & 1 & 0,85 & 0,63 & 3,15 & 4,64 & 2 & 3 & 1,59 & 1,09 & 3,37 & 6,05 \\
\hline Malvastrum coromandelianum & 1 & 1 & 0,83 & 0,44 & 2,72 & 3,98 & 7 & 9 & 5,98 & 5,70 & 4,05 & 15,73 & - & - & - & - & - & - \\
\hline Cenchrus echinatus & 1 & 1 & 0,83 & 0,44 & 2,72 & 3,98 & 1 & 1 & 0,85 & 0,63 & 3,15 & 4,64 & 2 & 2 & 1,59 & 0,73 & 2,25 & 4,56 \\
\hline Emilia sonchifolia & 1 & 1 & 0,83 & 0,44 & 2,72 & 3,98 & 4 & 4 & 3,42 & 2,53 & 3,15 & 9,10 & 4 & 6 & 3,17 & 2,18 & 3,37 & 8,73 \\
\hline Ageratum conyzoides & 1 & 2 & 0,83 & 0,88 & 5,43 & 7,14 & 4 & 4 & 3,42 & 2,53 & 3,15 & 9,10 & 3 & 5 & 2,38 & 1,82 & 3,74 & 7,94 \\
\hline Mollugo verticillata & 1 & 1 & 0,83 & 0,44 & 2,72 & 3,98 & 1 & 1 & 0,85 & 0,63 & 3,15 & 4,64 & - & - & - & - & - & - \\
\hline Crotalaria indica & 1 & 1 & 0,83 & 0,44 & 2,72 & 3,98 & 1 & 1 & 0,85 & 0,63 & 3,15 & 4,64 & - & - & - & - & - & - \\
\hline Amaranthus viridis & - & - & - & - & - & - & 1 & 1 & 0,85 & 0,63 & 3,15 & 4,64 & - & - & - & - & - & - \\
\hline Croton heliotropiifolius & - & - & - & - & - & - & 5 & 10 & 4,27 & 6,33 & 6,30 & 16,90 & 6 & 6 & 4,76 & 2,18 & 2,25 & 9,19 \\
\hline Desmodium adscendens & - & - & - & - & - & - & 2 & 3 & 1,71 & 1,90 & 4,73 & 8,33 & - & - & - & - & - & - \\
\hline Bidens pilosa & - & - & - & - & - & - & 2 & 2 & 1,71 & 1,27 & 3,15 & 6,13 & - & - & - & - & - & - \\
\hline Eleusine indica & - & - & - & - & - & - & - & - & - & - & - & - & 2 & 2 & 1,59 & 0,73 & 2,25 & 4,56 \\
\hline Parthenium hysterophorus & - & - & - & - & - & - & - & - & - & - & - & - & 1 & 1 & 0,79 & 0,36 & 2,25 & 3,40 \\
\hline Aeschynomene denticulata & - & - & - & - & - & - & - & - & - & - & - & - & 1 & 1 & 0,79 & 0,36 & 2,25 & 3,40 \\
\hline Total & 121 & 226 & 100 & 100 & 100 & 300 & 117 & 158 & 100 & 100 & 100 & 300 & 126 & 275 & 100 & 100 & 100 & 300 \\
\hline
\end{tabular}

Cultura Agronômica, Ilha Solteira, v.27, n.2, p.327-340, 2018 
Tabela 5. Parâmetros fitossociológicos das espécies de plantas daninhas, em ordem decrescente de número de presença em quadrados (NQ), número de indivíduos (NI), frequência relativa (FR), densidade relativa (DR), abundância relativa (AR) e índice de valor de importância (IVI) coletadas aos 49, 56 e 63 dias após a emergência do feijão-caupi (Vitória da Conquista-BA, 2015).

\begin{tabular}{|c|c|c|c|c|c|c|c|c|c|c|c|c|c|c|c|c|c|c|}
\hline \multirow{3}{*}{ Espécies } & \multicolumn{6}{|c|}{$49 \mathrm{DAE}$} & \multicolumn{6}{|c|}{$56 \mathrm{DAE}$} & \multicolumn{6}{|c|}{$63 \mathrm{DAE}$} \\
\hline & NQ & $\mathrm{NI}$ & FR & DR & AR & IVI & NQ & NI & FR & DR & AR & IVI & NQ & NI & FR & DR & AR & IVI \\
\hline & & $--\%$ & ---- & & & & & & 0 & & & & & & & & & \\
\hline$\overline{\text { Panicum maximum }}$ & 25 & 58 & 17,86 & 22,05 & 4,41 & 44,32 & 22 & 56 & 18,64 & 27,45 & 6,76 & 52,86 & 13 & 19 & 12,04 & 11,18 & 4,73 & 27,94 \\
\hline Portulaca mucronata & 15 & 20 & 10,71 & 7,60 & 2,54 & 20,85 & 9 & 13 & 7,63 & 6,37 & 3,84 & 17,84 & 13 & 26 & 12,04 & 15,29 & 6,47 & 33,80 \\
\hline Sida cordifolia & 10 & 15 & 7,14 & 5,70 & 2,85 & 15,70 & 8 & 9 & 6,78 & 4,41 & 2,99 & 14,18 & 3 & 3 & 2,78 & 1,76 & 3,24 & 7,78 \\
\hline Solanum americanum & 8 & 10 & 5,71 & 3,80 & 2,38 & 11,89 & 6 & 7 & 5,08 & 3,43 & 3,10 & 11,62 & 2 & 3 & 1,85 & 1,76 & 4,85 & 8,47 \\
\hline Digitaria horizontalis & 7 & 15 & 5,00 & 5,70 & 4,08 & 14,78 & 3 & 3 & 2,54 & 1,47 & 2,66 & 6,67 & 1 & 1 & 0,93 & 0,59 & 3,24 & 4,75 \\
\hline Herissantia crispa & 7 & 10 & 5,00 & 3,80 & 2,72 & 11,52 & 5 & 5 & 4,24 & 2,45 & 2,66 & 9,35 & 12 & 12 & 11,11 & 7,06 & 3,24 & 21,41 \\
\hline Sida rhombifolia & 6 & 6 & 4,29 & 2,28 & 1,90 & 8,47 & 2 & 2 & 1,69 & 0,98 & 2,66 & 5,33 & 3 & 3 & 2,78 & 1,76 & 3,24 & 7,78 \\
\hline Solanum mauritianum & 6 & 6 & 4,29 & 2,28 & 1,90 & 8,47 & 4 & 4 & 3,39 & 1,96 & 2,66 & 8,01 & 1 & 1 & 0,93 & 0,59 & 3,24 & 4,75 \\
\hline Pyrostegia venusta & 6 & 14 & 4,29 & 5,32 & 4,44 & 14,05 & - & - & - & - & - & - & - & - & - & - & - & - \\
\hline Dichondra sericea & 6 & 17 & 4,29 & 6,46 & 5,39 & 16,14 & 6 & 9 & 5,08 & 4,41 & 3,99 & 13,48 & 14 & 47 & 12,96 & 27,65 & 10,86 & 51,47 \\
\hline Brachiaria plantaginea & 5 & 7 & 3,57 & 2,66 & 2,66 & 8,90 & - & - & - & - & - & - & 1 & 1 & 0,93 & 0,59 & 3,24 & 4,75 \\
\hline Blainvillea biaristata & 5 & 12 & 3,57 & 4,56 & 4,56 & 12,70 & 8 & 11 & 6,78 & 5,39 & 3,65 & 15,82 & 8 & 8 & 7,41 & 4,71 & 3,24 & 15,35 \\
\hline Hyptis suaveolens & 5 & 9 & 3,57 & 3,42 & 3,42 & 10,42 & 3 & 7 & 2,54 & 3,43 & 6,20 & 12,17 & 6 & 14 & 5,56 & 8,24 & 7,55 & 21,34 \\
\hline Ageratum conyzoides & 4 & 5 & 2,86 & 1,90 & 2,38 & 7,14 & 3 & 3 & 2,54 & 1,47 & 2,66 & 6,67 & 5 & 5 & 4,63 & 2,94 & 3,24 & 10,81 \\
\hline Croton heliotropiifolius & 4 & 11 & 2,86 & 4,18 & 5,23 & 12,27 & 5 & 12 & 4,24 & 5,88 & 6,38 & 16,50 & 1 & 1 & 0,93 & 0,59 & 3,24 & 4,75 \\
\hline Commelina benghalensis & 4 & 18 & 2,86 & 6,84 & 8,56 & 18,26 & 5 & 15 & 4,24 & 7,35 & 7,97 & 19,56 & 4 & 5 & 3,70 & 2,94 & 4,05 & 10,69 \\
\hline Rhynchelytrum repens & 3 & 4 & 2,14 & 1,52 & 2,54 & 6,20 & - & - & - & - & - & - & 1 & 1 & 0,93 & 0,59 & 3,24 & 4,75 \\
\hline Pavonia cancellata & 2 & 2 & 1,43 & 0,76 & 1,90 & 4,09 & 1 & 1 & 0,85 & 0,49 & 2,66 & 3,99 & 2 & 2 & 1,85 & 1,18 & 3,24 & 6,26 \\
\hline Cenchrus echinatus & 2 & 6 & 1,43 & 2,28 & 5,71 & 9,42 & 7 & 14 & 5,93 & 6,86 & 5,31 & 18,11 & - & - & - & - & - & - \\
\hline Solanum paniculatum & 2 & 2 & 1,43 & 0,76 & 1,90 & 4,09 & 4 & 4 & 3,39 & 1,96 & 2,66 & 8,01 & 2 & 2 & 1,85 & 1,18 & 3,24 & 6,26 \\
\hline Senna obtusifolia & 1 & 1 & 0,71 & 0,38 & 1,90 & 3,00 & 4 & 9 & 3,39 & 4,41 & 5,98 & 13,78 & 2 & 2 & 1,85 & 1,18 & 3,24 & 6,26 \\
\hline Pavonia sidifolia & 1 & 6 & 0,71 & 2,28 & 11,41 & 14,41 & 1 & 1 & 0,85 & 0,49 & 2,66 & 3,99 & 3 & 3 & 2,78 & 1,76 & 3,24 & 7,78 \\
\hline Emilia sonchifolia & 1 & 1 & 0,71 & 0,38 & 1,90 & 3,00 & 2 & 2 & 1,69 & 0,98 & 2,66 & 5,33 & 2 & 2 & 1,85 & 1,18 & 3,24 & 6,26 \\
\hline Setaria geniculata & 1 & 4 & 0,71 & 1,52 & 7,61 & 9,84 & 4 & 4 & 3,39 & 1,96 & 2,66 & 8,01 & 4 & 4 & 3,70 & 2,35 & 3,24 & 9,29 \\
\hline Diodia teres & 1 & 1 & 0,71 & 0,38 & 1,90 & 3,00 & 2 & 7 & 1,69 & 3,43 & 9,30 & 14,42 & 1 & 1 & 0,93 & 0,59 & 3,24 & 4,75 \\
\hline Acanthospermum australe & 1 & 1 & 0,71 & 0,38 & 1,90 & 3,00 & - & - & - & - & - & - & - & - & - & - & - & - \\
\hline Waltheria indica & 2 & 2 & 1,43 & 0,76 & 1,90 & 4,09 & - & - & - & - & - & - & - & - & - & - & - & - \\
\hline Malvastrum coromandelianum & - & - & - & - & - & - & 2 & 3 & 1,69 & 1,47 & 3,99 & 7,15 & 2 & 2 & 1,85 & 1,18 & 3,24 & 6,26 \\
\hline Cynodon dactylon & - & - & - & - & - & - & 2 & 3 & 1,69 & 1,47 & 3,99 & 7,15 & 2 & 2 & 1,85 & 1,18 & 3,24 & 6,26 \\
\hline Total & 140 & 263 & 100 & 100 & 100 & 300 & 118 & 204 & 100 & 100 & 100 & 300 & 108 & 170 & 100 & 100 & 100 & 300 \\
\hline
\end{tabular}

Cultura Agronômica, Ilha Solteira, v.27, n.2, p.327-340, 2018 


\section{Caracterização das principais espécies da comunidade infestante}

A espécie $D$. horizontalis, conhecida popularmente como capim-colchão, pode ser considerada a planta daninha com maior potencial para causar prejuízos à cultura do feijãocaupi. Essa planta possui desenvolvimento rápido e agressivo em áreas cultivadas e é relatada como problema em mais de 60 países por causa da infestação em mais de 30 culturas de importância econômica (DIAS et al., 2007). De acordo com Kissmann e Groth (2000), no Brasil, esta espécie pode ocorrer regularmente em várias culturas "de primavera" ou "de verão", constituindo sérios problemas, tais como apresentar vantagens em relação às culturas em situações de estresse, como déficit hídrico, e por apresentar efeitos alelopáticos sobre várias espécies cultivadas.

A espécie $P$. maximum, conhecida como capim colonião, extrai grandes quantidades de nutrientes do solo, sendo também muito agressiva e competitiva em áreas agrícolas (OLIVEIRA e FREITAS, 2008). Os autores ainda relatam que a parte subterrânea dessa espécie pode resistir à queimada, ocorrendo logo após, uma rápida rebrota e reinfestação da área. O desenvolvimento rápido da espécie é um mecanismo de sobrevivência às condições adversas.

Marques et al. (2010), avaliando a composição florística de plantas daninhas na cultura do feijão-caupi, observaram altos valores de índice de valor de importância para $D$. horizontalis (82,78 aos $30 \mathrm{DAE}$ ) devido principalmente ao aumento da densidade relativa das espécies desse gênero, superando os valores de frequência relativa e abundância relativa. Corrêa et al. (2011), também, observaram altos valores de índice de valor de importância para $D$. horizontalis (140,83 aos 60 DAE) na cultura do feijão-caupi devido ao aumento da densidade e da abundância relativa.

De acordo com Tavares et al. (2013), no período de verão-outono, D. horizontalis foi uma das espécies mais importantes na comunidade infestante do feijoeiro BRS Embaixador em Urutaí, GO.

Borchardtt et al. (2011), avaliando a interferência de plantas daninhas na cultura do feijão cultivado na época verão-outono observaram, na comunidade infestante, que $D$. horizontalis apresentou maior importância relativa pois atingiu altas taxas de frequência relativa, dominância relativa e densidade de até $95,3 \%$, promovendo perdas de até $35 \%$ no rendimento de grãos do feijoeiro.

Plantas da família Portulacaceae também foram encontradas em todos os períodos avaliados, tais como P. oleracea e P. mucronata. De acordo com Lorenzi (2008), as espécies pertencentes à família Portulacaceae são altamente prolíficas e se adaptam bem a solos férteis, o que pode explicar a presença dessas plantas na área.

A espécie $D$. horizontalis apresentou uma abundância relativa alta aos 7 DAE (15,5 $\%$ ) e uma abundância relativa baixa aos 35 DAE (4,8 \%) e 49 DAE $(3,7 \%)$ (Tabela 3, 4 e 5). Essa redução em relação à abundância relativa pode estar associada ao fato dessas plantas entrarem em senescência no final do período do experimento, além da competição

Cultura Agronômica, Ilha Solteira, v.27, n.2, p.327-340, 2018 
com outras plantas. De acordo com Silva et al. (2009) à medida que a densidade de plantas daninhas aumenta em determinada área, a competição inter e intra-específica é intensificada, de forma que as plantas daninhas com maior estatura e com maior desenvolvimento tornamse dominantes, ao passo que as menores são suprimidas ou morrem.

Pitelli (2000) afirmam que a falta de conhecimentos básicos sobre a biologia e ecologia de plantas daninhas é limitante para a implantação de programas de manejo integrado dessas plantas. Segundo Freitas et al. (2009), as plantas daninhas são consideradas um dos principais fatores que refletem na redução quantitativa e qualitativa da produção de feijão-caupi, além de elevar os gastos operacionais de colheita, secagem e beneficiamento dos grãos, sendo o seu controle considerado um dos principais componentes nos custos de produção.

Contudo, as diferenças encontradas entre os parâmetros fitossociológicos das espécies e as épocas avaliadas, podem ser importantes para o planejamento do manejo das plantas daninhas, uma vez que, a partir desses parâmetros analisados, podem ser adotadas práticas culturais que minimizam os danos causados pela competição entre plantas daninhas. Dessa forma, torna-se de fundamental o conhecimento das espécies daninhas e suas populações durante todo o ciclo da cultura, especialmente no período crítico de prevenção da interferência, que poderá refletir diretamente na qualidade do produto final das culturas.

\section{CONCLUSÃO}

Foram identificadas 43 espécies de plantas daninhas distribuídas em 36 gêneros e 17 famílias botânicas.

As famílias com maior número de espécies foram Poaceae, Asteraceae e Malvaceae.

As espécies que apresentaram maiores valores para os pârametros fotossociológicos na cultura do feijão-caupi foram Portulaca mucronata, D. horizontalis e Panicum maximum, sendo as duas últimas as espécies que apresentaram maiores IVI.

\section{AGRADECIMENTOS}

À Universidade Estadual do Sudoeste da Bahia (UESB) e a Fundação de Amparo à Pesquisa do Estado da Bahia (FAPESB).

\section{REFERÊNCIAS BIBLIOGRÁFICAS}

BATISTA, P. S. C.; OLIVEIRA, V. S.; CAXITO, A. M.; CARVALHO, A. J.; ASPIAZÚ, I. Phytosociological survey of weeds in cultivars of common beans with different types of growth in the north of Minas Gerais. Planta Daninha, Viçosa, v. 34, n. 3, p.497-507, 2016. Disponível em: <http://dx.doi.org/10.1590/s0100-83582016340300010>. Acesso em: 04 mai. 2018.

Cultura Agronômica, Ilha Solteira, v.27, n.2, p.327-340, 2018 
BORCHARTT, L.; JAKELAITIS, A.; VALADÃO, F. C. A.; VENTUROSO, L. A. C.; SANTOS, C. L. Períodos de interferência de plantas daninhas na cultura do feijoeirocomum (Phaseolus vulgaris L.). Revista Ciência Agronômica, Fortaleza, v. 42, n. 3, p.725-734, 2011. Disponível em: <http://ccarevista.ufc.br/seer/index.php/ccarevista/article/view/1176>. Acesso em: 04 mai. 2018.

CORRÊA, M. J. P.; ARAúJO, M. S.; Silva, M. R. M.; FreitaS, A. C. R. de. Levantamento da flora espontânea na cultura do feijão-caupi sob manejo de capoeira triturada no município de Santa Luzia do Paruá - MA. Cadernos de Agroecologia, Fortaleza, v. 6, n. 2 p.1-5, 2011. Disponível em: <http://revistas.abaagroecologia.org.br/index.php/cad/article/view/10772/7264>. Acesso em: 04 mai. 2018.

CORRÊA, M. J. P; ALVES, G. L.; ROCHA, L. G. F; SILVA, M. R. M. Períodos de interferência de plantas daninhas na cultura do feijão caupi. Revista de Ciências Agroambientais, Alta Floresta, v. 13, n. 2, p.50-56, 2015. Disponível em: <https://periodicos.unemat.br/index.php/rcaa/article/view/1183/1257>. Acesso em: 04 mai. 2018.

DIAS, A. C. R.; CARVAlHO, S. J. P.; NICOLAI, M.; CHRISTOFFOLETI, P. J. Problemática da ocorrência de diferentes espécies de capim colchão (digitaria spp.) na cultura da cana-de-açúcar. Planta Daninha, Viçosa, v. 25, n. 2, p.489-499, 2007. Disponível em: <http://dx.doi.org/10.1590/S0100-83582007000300008>. Acesso em: 04 mai. 2018.

FREIRE FILHO, F. R.; RIBEIRO, V. Q.; ROCHA, M. M.; NOGUEIRA, M. S. R.; RODRIGUES, E. V. Produção, melhoramento genético e potencialidades do feijão-caupi no Brasil. In: REUNIÃO NACIONAL DE BIOFORTIFICAÇÃO, 4, 2011, Teresina. Resumos...Teresina: Embrapa Meio Norte, 2011. p. 1-21. 1 CD-ROM.

FREITAS. F. C. L.; MEDEIROS. V. F. L. P.; GRANGEIRO; L; C.; SILVA, M. G. O.; NASCIMENTO, P. G. M. L.; NUNES, G. H. Interferência de plantas daninhas na cultura do feijão-caupi. Planta Daninha, Viçosa, v. 27, n. 2, p.241-47, 2009. Disponível em: <http://dx.doi.org/10.1590/S0100-83582009000200005>. Acesso em: 04 mai. 2018. 04 maio. 2018.

FREITAS, W. K.; MAGALHÃES, L. M. S. Métodos e parâmetros para estudo da vegetação com ênfase no estrato arbóreo. Floresta e Ambiente, Seropédica, v. 19, n. 4, p.520-540, 2012. Disponível em: <http://dx.doi.org/10.4322/floram.2012.054>. Acesso em: 04 maio. 2018.

ISAAC, R, A.; GUIMARÃES, S. C. Banco de sementes e flora emergente de plantas daninhas. Planta Daninha, Viçosa, v. 26, n. 3, p.521-30, 2008. Disponível em: <http://dx.doi.org/10.1590/S0100-83582008000300007>. Acesso em: 04 mai. 2018.

KISSMANN, K. G.; GROTH, D. Plantas infestantes e nocivas. 2.ed. São Paulo: BASF, 
2000. Tomo III, 723 p.

LORENZI H. Plantas daninhas do Brasil: terrestres, aquáticas, parasitas e tóxicas.4. ed. . Nova Odessa: Instituto Plantarum, 2008. 672 p.

MARQUES, L. J. P.; SILVA, M. R. M.; ARAÚJO, M. S.; LOPES, G. S.; CORRÊA, M. J. P.; FREITAS, A. C. R.; MUNIZ, F. H. Composição florística de plantas daninhas na cultura do feijão-caupi no sistema de capoeira triturada. Planta Daninha, Viçosa, v. 28, n.especial, p. 953-61, 2010. Disponível em: <http://dx.doi.org/10.1590/S0100-83582010000500003>. Acesso em: 04 mai. 2018.

MUELLER-DOMBOIS, D.; ELLENBERG, H. Aims and methods of vegetation ecology. New York: John Wiley \& Sons; 1974. 547 p.

OLIVEIRA, A, R.; FREITAS, S. P. Levantamento fitossociológico de plantas daninhas em áreas de produção de cana-de-açúcar. Planta Daninha, Viçosa, v. 26, n. 1, p.33-46, 2008. Disponível em: <http://dx.doi.org/10.1590/S0100-83582008000100004>. Acesso em: 04 mai. 2018.

OLIVEIRA, L. S. DE; CANUTO, R. S. O.; CANUTO, D. M. F. O. Levantamento fitossociológico de plantas daninhas na cultura do feijão-caupi no agreste alagoano. Enciclopédia Biosfera, Goiânia, v. 14, n. 25, p.861, 2017. Disponível em: <doi: 10.18677/EnciBio_2017A69>. Acesso em: 04 mai. 2018.

PINOTTI, E. B.; BICUDO, S. J.; CURCELLI, F. E.; DOURADO, W. S. Levantamento florístico de plantas daninhas na cultura da mandioca no município de Pompéia - SP. Revista Raízes e Amidos Tropicais, São Paulo, v. 6, p. 120-125, 2010. Disponível em: $<$ http://energia.fca.unesp.br/index.php/rat/article/view/1111/1168>. Acesso em: 04 mai. 2018 .

PITELLI, R. A. Estudos fitossociológicos em comunidades infestantes de agrossistemas. Jornal Conserb, São Paulo, v. 1, n. 2, p.1-7, 2000.

SANTI, A. L.; BONA, S. D.; LAMEGO, F. P.; BASSO, C. J.; EITELWEIN, M. T.; CHERUBIN, M. R.; KASPARY, T. E.; RUCHEL, Q.; GALLON, M. Phytosociological variability of weeds in soybean Field. Planta Daninha, Viçosa, v. 32, n.1, p. 39-49, 2014. Disponível em: http://dx.doi.org/10.1590/S0100-83582014000100005. Acesso em: 04 mai. 2018.

SILVA, A. F.; CONCENÇO, G.; ASPIAZÚ, I.; FERREIRA, E. A.; GALON, L.; COELHO, A. T. C. P.; SILVA, A. A.; FERREIRA, F. A. Interferência de plantas daninhas em diferentes densidades no crescimento da soja. Planta Daninha, Viçosa, v. 27, n. 1, p.75-84, 2009. Disponível em: <http://dx.doi.org/10.1590/S0100-83582009000100011>. Acesso em: 04 mai. 2018.

SILVA, D. A.; JOSÉ, A, A. A.; JOSÉ, M, A. A; PAUlO, R. R. R; R, D. M.; EVERTON, L. F.; PEDRO, H. S. M. Caracterização de plantas daninhas em área rotacionada de milho e feijão-caupi em plantio direto. Scientia Agropecuaria, Trujillo, v. 9, n. 1, p.7-15, 2018.

Cultura Agronômica, Ilha Solteira, v.27, n.2, p.327-340, 2018 
Disponível em: <http://dx.doi.org/10.17268/sci.agropecu.2018.01.01>. Acesso em: 04 mai. 2018.

TAVARES, C. J.; JAKELAITIS, A.; REZENDE, B. P. M.; CUNHA, P. C. R. da. Fitossociologia de plantas daninhas na cultura do feijão. Revista Brasileira de Ciências Agrárias, Recife, v. 8, n. 1, p.27-32, 2013. Disponível em: <doi:10.5039/agraria.v8i1a1849>. Acesso em: 04 mai. 2018. 